\title{
A formação dos conceitos em Vigotski: replicando um experimento
}

\author{
Maria Sara de Lima Dias \\ Universidade Tuiuti do Paraná - PR \\ Universidade Positivo - PR \\ Roberta Kafrouni \\ Universidade Tuiuti do Paraná - PR \\ Camilla Silva Baltazar \\ Universidade Positivo - PR \\ Juliana Stocki \\ Universidade Positivo - PR
}

\section{Resumo}

A pesquisa apresentada neste artigo teve por objetivo replicar o experimento sobre formação de conceitos proposto por Vigotski. O experimento investigava o desenvolvimento e a organização do pensamento conceitual na população adulta. Na presente pesquisa a amostra foi composta por 20 estudantes universitários de diversos cursos, de idades entre 18 e 24 anos. $O$ instrumento de coleta de dados foi um conjunto de vinte e dois blocos de madeira de cores, formas, alturas e larguras diferentes que tinham em sua base palavras sem um significado previamente conhecido pelos participantes, e este significado o experimento deveria identificar. A aplicação do instrumento foi registrada em vídeo para posterior análise. Observou-se na aplicação do instrumento que não houve regularidade em relação às etapas percorridas durante a formação do conceito, mas foi possível identificar o papel da linguagem no processo de generalização.

Palavras-chave: Formação de conceito; Vigotski; pensamento.

\section{Vigotski's concept formation: replicating an experiment}

\begin{abstract}
The main goal of this research was to replicate an experiment established by Vigotski about concept formation. The experiment investigated the development and organization of conceptual thinking in the adult population, and questioned the steps followed in the formation of a new concept and how adults can understand the meaning of a new word. The random sample consisted of 20 university students from various courses, aged between 18 and 24 years. The method of research consists of an application of an instrument composed by a set of wooden blocks of colors, shapes, heights and widths associated with nonsense words with which the participant should seek a solution to a proposed problem. The recorded and transcribed speeches in the sessions were subjected to analysis. It was observed that the application of the instrument that there was no regularity relating to steps taken during the formation of the concept. We demonstrate that generalization is the main function of language, without which it is impossible to acquire the experience and established itself as the basis of complex thought.
\end{abstract}

Keywords: concept formation; Vigotski; thinking.

\section{La formación dos conceptos en Vygotsky: replicando un experimento}

\section{Resumen}

La investigación presentada en este artículo tuvo por objetivo replicar el experimento sobre formación de conceptos propuesto por Vygotsky. El experimento investigaba el desarrollo y la organización del pensamiento conceptual en la populación adulta. En la presente investigación el muestreo fue compuesto por 20 estudiantes universitarios de diversos cursos, de edades entre 18 y 24 años. El instrumento de recolecta de datos fue un conjunto de veintidós bloques de madero de colores, formas, alturas y anchos diferentes que tenían en su base palabras sin un significado previamente conocido por los participantes, y este significado el experimento debería identificar. La aplicación del instrumento fue registrada en vídeo para posterior análisis. Se observó en la aplicación del instrumento que no hubo regularidad en relación a las etapas recorridas durante la formación del concepto, pero fue posible identificar el papel del lenguaje en el proceso de generalización.

Palabras-clave: formación de conceptos; Vigotski; pensamiento. 


\section{Introdução}

Em seu texto "Pensamento e linguagem" (1933/1998) Vigotski propôs um método para investigação de conceitos cujos resultados tornaram-se a base de sua teoria sobre o desenvolvimento de conceitos. Consistia em um método experimental que o autor denominou de método da dupla estimulação. Isso significava que, em vez de oferecer ao participante da pesquisa um estímulo e observar uma resposta, ofereciam-se recursos auxiliares que lhe permitissem desenvolver uma resposta, e então se analisava a história do comportamento. Este método era consistente com a perspectiva de Vigotski segundo a qual o comportamento humano não é apenas a resposta a um determinado estímulo, mas é constituído com o auxílio de mediações - os signos; portanto o signo não determina um comportamento, mas permite ao indivíduo sua constituição em um processo complexo que deve ser acompanhado pelo pesquisador a fim de ser compreendido.

Diante da proposta inovadora de Vigotski para a compreensão das funções psicológicas superiores, surpreende que os pesquisadores não se tenham aprofundado em seu método experimental para o estudo da formação de conceitos, embora suas conclusões sejam amplamente aceitas e difundidas. Prova disto é a inexistência de pesquisas que procurem replicar ou desenvolver o método.

A linguagem é indispensável à formação de conceitos, a qual começa na infância e prossegue desenvolvendo-se até a adolescência; mas este processo não é natural, ele é significativamente influenciado por aspectos sociais como, por exemplo, a escolarização. O desenvolvimento de conceitos não é estático nem termina com a aquisição de palavras, antes a aquisição e uso de palavras pela criança põe em marcha o desenvolvimento de conceitos.

O objetivo desta pesquisa consistiu em captar com o máximo de aproximação possível o que seriam as complexas e múltiplas determinações da linguagem envolvidas na replicação de seu experimento com adultos. Nela buscamos aprofundar o conhecimento sobre a temática e estudar como se desenvolve a formação de um novo conceito, replicando o método da dupla estimulação funcional utilizado por Vigotski no estudo da formação de conceitos.

O estudo elaborado por Vigotski (1994, p. 127) “(...) se propõe a descobrir o papel das palavras e das características de seu uso funcional no processo de formação de conceitos". Outro aspecto do estudo é que possibilita investigar o modo como o sujeito utiliza os signos como meio para dirigir suas operações intelectuais, uma vez que a resolução do problema proposto com a aplicação do instrumento corresponde à real formação de conceitos.

Segundo Vigotski (1998, p. 190), “(...) a palavra é o microcosmo da consciência”, é um instrumento de análise da informação, visto que percorre um caminho até ser internalizada e adquirir a função de analisar e generalizar um objeto; o conceito é o mediador que permite adquirir o significado da palavra. O objetivo principal desta pesquisa foi compreender as etapas percorridas no processo da formação de um novo conceito, observar este processo na população adulta e descrever como um novo conceito é internalizado, isto é, verificar como os participantes conseguem apreender o significado do novo conceito.

\section{Revisão de literatura}

Todas as informações que recebemos precisam ser organizadas para assegurarmos a nossa sobrevivência dentro de um grupo social. Quando estamos inseridos em um grupo social utilizamos uma base categórica comum que nos permite organizar nossas experiências com o mundo. Essa base categórica corresponde aos distintos conceitos que formamos ao longo da vida (Nébias, 1998). Para explicar a aprendizagem de conceitos, alguns autores trazem reflexões distintas sobre o processo, entre eles Piaget (1996), Ausubel (1963 conforme citado por Moreira, Caballero, \& Rodriguez, 1997) e Skinner (2003), que buscam deixar clara a forma de desenvolvimento de nossa linguagem, embora não cheguem a um consenso sobre a formação dos novos conceitos.

De acordo com Piaget (1996), a aprendizagem decorre de um processo de equilibração que se desenvolve por meio da assimilação e da acomodação de esquemas que formam estruturas mentais capazes de atingir o pensamento conceitual. Montoya (2006) aponta que um conceito "(...) é produto das mudanças que envolverão necessariamente reorganizações por abstrações reflexionantes" (p. 124). Ausubel (conforme citado por Moreira, \& cols. 1997) utiliza a expressão aprendizagem significativa e explica que é por meio desse processo que um novo conhecimento se estabelece. Explica o autor: "A aprendizagem significativa é o mecanismo humano por excelência para adquirir e armazenar a vasta quantidade de ideias e informações" (Ausubel, 1963, p. 58 conforme citado por Moreira, \& cols 1997, p. 19). Para Skinner (2003), os conceitos seriam adquiridos por meio do processo de discriminação e generalização. A discriminação ocorre quando o ambiente passa a exercer controle sobre a emissão de um comportamento. A generalização ocorre quando esse comportamento é emitido em outras situações semelhantes. Pozo (1998) aponta que, nessa teoria, a formação de conceitos se estabeleceria por associações entre estímulos e respostas.

Vigotski, por sua vez, explica que temos de entender primeiro os meios pelos quais o homem aprende a organizar e dirigir o seu comportamento (1934/1998). Todas as funções psíquicas superiores são processos mediados por signos. O signo é a palavra, e desempenha um papel importante na formação de um conceito. O conceito tem origem social e sua formação inclui a relação com os outros (Goes, \& Cruz, 2006). De acordo com Gerhardt (2010), Vigotski defende o papel estruturador da aquisição de conceitos no desenvolvimento cognitivo.

Quanto ao estudo da formação de conceitos, Vigotski critica dois tipos de método. O primeiro é chamado de método de definição, que tem como principal objetivo analisar os 
conceitos prontos e acabados através de uma definição verbal. De acordo com Vigotski (1934/1998), embora tenha sido amplamente utilizado, esse método apresenta duas falhas que dificultam uma investigação, a saber: 1- esse método trabalha com o resultado final do processo da formação de conceitos, ou seja, com um elemento acabado, em vez da análise do processo, é dada ênfase ao produto obtido; 2- o método de definição trabalha com a palavra, ignorando que o conceito, principalmente para a criança, está relacionado a um material sensível no qual emergem a percepção e a elaboração. Ao captar somente o elemento verbal do conceito não se apreende o processo de sua formação em sua totalidade, sendo que por meio deste método o significado de uma palavra para a criança é atribuído mais às relações dadas e aprendidas entre famílias isoladas de palavras do que ao verdadeiro reflexo dos conceitos da criança.

$\mathrm{O}$ segundo tipo de método consiste em propor à criança que identifique características similares entre uma série de elementos abstraindo-as das demais características a que está perceptualmente relacionada. A falha dessa segunda tendência é que troca o processo de síntese por um processo parcial e deixa de lado o papel da palavra e do signo na formação de conceitos reduzindo-o ao processo de abstração, separando a característica principal da formulação de conceitos, que é a sua relação com a palavra.

Estes dois métodos citados por Vigotski (1934/1998) trazem dois importantes problemas que os tornam impróprios para a investigação. O primeiro é um método que se realiza sobre o produto final do processo de formação de conceitos, descartando sua dinâmica, limitando-se a gerar uma reprodução verbal de definições ministradas a partir do exterior. Trata-se de um teste do conhecimento e da experiência da criança ou do seu desenvolvimento linguístico. Em segundo lugar, este método, ao focar na palavra, ignora a percepção e a formação do material sensorial que participam na elaboração do conceito.

Em síntese, o que ocorre com esses dois métodos é que eles fazem uma separação, ora apartando a palavra do material sensível, ora focalizando o material sem a palavra. Buscando superar essas duas tendências, Vigotski e seus colaboradores criaram o método de busca modificado, que se caracterizava por diversas reformulações na proposta inicial do método de Ach. Para estudar e analisar o processo, Vigotski utiliza um método desenvolvido por um de seus colaboradores, L. S. Sakharov. Esse método introduz palavras sem sentido aparente, e também conceitos artificiais relacionados a cada uma dessas palavras (Vigotski, 1934/1998). Dessa forma, reproduz em escala reduzida as condições iniciais da aquisição do significado das palavras no desenvolvimento infantil, buscando artificialmente o processo para poder acompanhá-lo. Vigotski e seus colaboradores (1934/1998) chamaram a este tipo de método de investigação experimental de "método da dupla estimulação". A principal característica deste método é a análise do desenvolvimento dos processos psíquicos superiores, com o auxílio de duas séries de estímulos cada uma atuando com uma função distinta em relação ao sujeito que está realizando a atividade. Uma série de estímulos atua na qualidade de objetos que direcionam a atividade do sujeito que a realiza. O experimento consiste na apresentação de figuras de tamanhos, larguras, formas e cores diferentes. Embaixo de cada figura há uma palavra sem sentido para o participante, mas que representa um conjunto de atributos dos objetos apresentados. Uma peça é virada como amostra e ao sujeito caberá separar as peças e formar o grupo que considera condizente com a palavra sem sentido apresentada. Após cada tentativa do sujeito em realizar a atividade, o experimentador vira uma das peças erradamente escolhida e incentiva o sujeito a tentar novamente. Conforme o sujeito vai tentando formar os grupos e o experimentador vai virando as peças erradas, o número de peças viradas aumenta; assim o sujeito começa a obter indícios das características referentes às palavras sem sentido, passando a formar seus respectivos grupos (Vigotski, 1934/1998).

Inicialmente o significado da palavra tem para a criança uma conotação afetiva. Posteriormente no início da vida escolar dominam as impressões concretas sobre a experiência direta real e prática. As etapas seguintes movem-se em direção a sistemas mais complexos de enlaces e relações abstratas. A palavra passa a representar um conjunto de objetos agrupados a partir da abstração de características relevantes desses objetos. A palavra torna-se, assim, um instrumento de análise da informação do mundo externo que a pessoa internaliza (Luria, 1987). Este desenvolvimento de conceitos é, em grande medida, auxiliado pela escolarização, pois o conhecimento formal inaugura uma nova organização de conceitos que parte do abstrato para o concreto, que são os conceitos científicos. Os conceitos científicos terão impacto na reorganização dos conceitos espontaneamente formados.

Assim, a aprendizagem de uma nova palavra é apenas o início de um grande processo de desenvolvimento. Embora o significado da palavra sempre seja um ato de generalização, ele se modifica à medida que a criança se depara com outras situações de uso da palavra e se desenvolvem seus processos intelectuais de abstração e generalização (Goes, \& Cruz, 2006).

Segundo Vigotski (2000), o estabelecimento de relações lógicas pelas quais certos elementos podem ser agrupados e dar origem a um conceito expresso por um signo verbal somente ocorre por volta dos doze anos. Depois desse período o pensamento alcança um desenvolvimento adequado para obter uma melhor compreensão de todas as situações do mundo e trabalhar abstratamente (Vigotski, 1934/1998).

Os adolescentes formam e utilizam um conceito certo numa situação concreta, mas apresentam dificuldade em demonstrar esse conceito por palavras, e a definição verbal aparece muito aquém daquilo que se espera, tendo-se em vista a forma como eles o utilizaram. Tal dificuldade também é observável no tocante ao pensamento dos adultos, mesmo em níveis de desenvolvimento mais altos. Este ponto mostra que os conceitos evoluem de modo distinto da elaboração 
intencional e consciente das experiências lógicas (Vigotski, 1934/1998).

Para Vigotski (1934/1998), a formação de conceitos percorre três etapas. Na primeira fase a criança pequena começa a formar os conceitos quando se agrupa certo número de objetos de modo desorganizado, ou "amontoado" para resolver um problema que os adultos resolvem, dado que conseguem elaborar um novo conceito.

O "amontoado" formado por um grupo de objetos nada parecidos e organizados sem qualquer lógica mostra um raciocínio difuso, em que o significado do signo ainda não está relacionado a um traço constante dos objetos. Nesta fase o significado das palavras para a criança não mostra mais do que uma conglomeração sincrética e vaga dos objetos individuais que as formam. Dada a sua origem sincrética, essa imagem é altamente inconstante.

A primeira fase da formação dos conceitos é composta de três estádios. No primeiro estádio a composição do grupo é determinada pela disposição espacial dos objetos analisados, isto é, por uma organização sincrética do campo visual da criança, que é criado ao acaso. No segundo estádio a imagem ou grupo sincrético desenvolvem-se como resultados da continuação, no espaço ou no tempo, dos elementos isolados, ou pelo fato de a percepção da criança levar a uma relação mais completa. Durante o terceiro estádio a imagem sincrética transforma-se em um arranjo mais complexo, composto de elementos extraídos de diferentes grupos ou "amontoados" já antes formados pela criança nos estádios anteriores. A gênese do conceito descrita por Vigotski engloba muitas variações de um tipo de pensamento chamado de "pensamento por complexos". O pensamento por complexos já é um pensamento mais objetivo, embora não mostre as relações objetivas da mesma forma que o pensamento conceitual. Um complexo é um agrupamento concreto de objetos ligados por uma conexão baseada em fatos, portanto todos os nexos existentes podem levar à formação de um complexo. A principal diferença entre um complexo e um conceito é que, enquanto o conceito ajunta elementos com atributos em comum, os complexos podem agrupar diversos elementos quantos for possível relacionar.

Na segunda fase dos complexos, Vigotski (1934/1998) observou cinco tipos de complexos. No primeiro tipo, o denominado de "complexo associativo", uma peça da amostra é agrupada com outra de acordo com algum elemento similar - como a cor, a altura ou a forma -, assim como por uma semelhança, um contraste ou pela simples aproximação com outras peças. O pensamento por complexos do segundo tipo consiste em combinar os objetos ou as impressões concretas, pois que os objetos são congregados com base em um traço que, embora seja diferente, complementa-se com outros elementos presentes.

Após essa fase há o complexo em cadeia, que se baseia na transmissão de um significado de um elemento para outro, formando assim uma corrente em que um elemento se ligará a outro com características semelhantes. Por vezes os elementos reunidos são considerados parecidos, devido mais a uma vaga impressão de semelhança do que a uma característica concreta. Isto leva ao quarto tipo de complexo, o chamado complexo difuso, que é marcado pela maleabilidade da própria característica que o liga aos seus elementos. Os grupos de objetos ou imagens concretas formam-se por meio de ligações difusas ou indefinidas (Vigotski, 1934/1998).

De acordo com Vigotski (1934/1998), as generalizações da criança nas áreas não sensoriais e não práticas do seu pensamento, as quais não podem ser facilmente observadas por meio da percepção ou da ação, são análogas na vida real dos complexos difusos presentes nas investigações sobre a formação de conceitos. A criança forma inúmeros complexos pela generalidade das ligações que abarca. Estes complexos são formados segundo as regras dos complexos concretos circunscritos.

Para completar o quadro do pensamento da criança há outro tipo de complexo, que é basicamente como aquele que constitui a ponte entre os complexos e o estádio final e superior do desenvolvimento da gênese dos conceitos (Vigotski,1934/1998).

Esse outro complexo é denominado de pseudoconceitos, pois as generalizações formadas no pensamento da criança aparentemente assemelham-se aos conceitos dos adultos e diferem psicologicamente de um verdadeiro conceito, apresentando-se ainda como um complexo. Uma criança produz um pseudoconceito quando cerca uma amostra com objetos que poderiam também ser agrupados com um conceito abstrato (Vigotski, 1934/1998).

Este tipo de complexo exerce um papel importante no pensamento da criança na vida real e é um elemento de mudança entre o pensamento por complexos e a verdadeira formação de conceitos. Os pseudoconceitos prevalecem sobre os demais complexos no pensamento da criança em idade pré-escolar. Tal fato ocorre porque os complexos que aparecem como significados das palavras não são ampliados pela criança, pois o caminho seguido por um complexo no seu desenvolvimento encontra-se predeterminado pelo significado que a palavra possui no vocabulário dos adultos (Vigotski, 1934/1998).

Segundo Vigotski (1934/1998), se analisarmos o percurso do significado das primeiras palavras, como resultado, irá aparecer uma combinação de duas formas, as quais, nas investigações do autor, são chamadas de complexos associativos e imagens sincréticas. A formação de complexos inicia-se quando uma mesma palavra tem diferentes significados em diferentes situações, desde que haja qualquer nexo associativo entre esses significados. Como as crianças com certa idade pensam por pseudoconceitos, haverá significados que não serão aceitos pela lógica dos adultos. Dependendo do que seja, ela pode ter diferentes atributos concretos, portanto pode ter vários nomes. A utilização de um ou de outro depende do complexo que seja ativado em um determinado momento (Vigotski, 1934/1998).

A importância fundamental dos complexos é a sua capacidade de unir e relacionar elementos entre si, exercendo um papel agregador de características indefinidas e criando um alicerce para futuras generalizações, enquanto 
o conceito é um fator que está acima da simples agregação de elementos. Para que um conceito seja formado é fundamental abstrair, isolar, analisar elementos separados de seu todo. Vigotski (1934/1998, p. 95) coloca que “(...) na verdadeira formação de conceitos, é igualmente importante unir e separar. A síntese deve combinar-se com a análise. $\mathrm{O}$ pensamento por complexos não é capaz de realizar essas duas operações".

Na terceira fase, a de conceitos potenciais, a criança forma agrupamentos considerando uma única característica inerente aos objetos, que pode ser a sua cor ou o seu formato. Os conceitos potenciais antecedem a fase da formação do conceito propriamente dito, pois como a criança ainda não alcançou uma completa abstração da palavra, muitas vezes ela utiliza apenas o seu atributo funcional.

Outro ponto relevante na teoria de Vigotski refere-se aos conceitos espontâneos e aos conceitos científicos. Os conceitos espontâneos são adquiridos nas práticas cotidianas da experiência pessoal do sujeito, já os conceitos científicos são formados por meio de um ensino formalizado sobre determinado objeto de conhecimento, ou seja, pela instrução formal no contexto escolar (Cazeiro, \& Lomônaco, 2011).

Para Vigotski, nos conceitos espontâneos a definição é feita através de suas características aparentes, enquanto nos conceitos científicos ocorre uma organização mais consistente e sistemática, sendo esses conceitos mediados por outros conceitos (Nébias, 1998).

As observações de Vigotski apontaram que um conceito se forma não por meio do jogo mútuo das associações, mas por meio de operações intelectuais em que todas as funções mentais elementares se comunicam numa combinação exclusiva. Esta operação é orientada pela utilização das palavras como forma de ativar a atenção, abstrair características e realizar a síntese e representação através de um signo.

De acordo com Vigotski (1934/1998), pode-se concluir que a formação dos conceitos desenvolve-se segundo duas trajetórias principais. A primeira é a formação "dos complexos", momento em que a criança une diversos elementos com uma característica similar. Este sistema percorre vários estádios. A segunda trajetória é a formação de "conceitos potenciais" e baseia-se no isolamento de alguns elementos comuns; as duas trajetórias são importantes nos processos genéticos e a palavra mantém a sua função principal, que é a de conduzir para a formação de novos conceitos.

\section{Método}

O trabalho foi realizado em uma sala de clínica de Psicologia de uma universidade situada em Curitiba, com a participação de vinte estudantes universitários de diversos cursos, de ambos os sexos e de idades entre 18 e 24 anos. O projeto foi aprovado pelo Comitê de Ética em Pesquisa (protocolo 011/2012). Como instrumento foi utilizado um conjunto de vinte e duas peças de blocos de madeira de cinco cores diferentes, com duas larguras (grossa e fina) e dois tamanhos (grande e pequeno). Na base de cada figura, de modo que o sujeito não pudesse ver, estava escrita uma das quatro palavras sem sentido: lag, bik, mur, cev. Independentemente da cor ou da forma, lag estava escrito nas figuras grossas e grandes; bik, nas finas e grandes; mur, nas grossas e pequenas; e cev, nas finas e pequenas.

Para todos os participantes, a peça inicial foi desvirada pelo experimentador, que passou a consigna "Separe todas as peças que você considera que fazem parte desta mesma palavra." Ao mesmo tempo a peça demonstrava que o triângulo preto era pertencente ao conceito da palavra cev (peça pequena e fina). No começo do experimento, todas as peças se encontravam misturadas sobre uma mesa diante do sujeito. O experimentador virava uma das peças (a que serviu para explicar a consigna), mostrava-a, lia seu nome e pedia que o sujeito escolhesse aquelas das restantes que ele considerasse que poderiam pertencer ao mesmo tipo. Uma vez que o sujeito fazia o que era pedido, o examinador virava uma das peças incorretamente escolhidas, mostrava que era de um tipo diferente e encorajava o sujeito a continuar. Depois de nova tentativa, era virada uma figura erradamente escolhida. Conforme o número de peças viradas aumentava, o sujeito ia adquirindo as bases para descobrir quais eram as características das figuras que levavam o mesmo nome. As sessões de aplicação do instrumento foram registradas em vídeo e posteriormente transcritas.

A análise do material coletado teve como objetivo identificar o percurso que o participante utilizou até o término da formação do conceito. Para alcançar esse propósito os dados foram analisados em duas etapas. Na primeira etapa as imagens foram descritas com base no registro contínuo, e na segunda etapa foram pontuadas as diferenças e semelhanças entre os comportamentos dos participantes. O desempenho dos participantes foi analisado por meio das seguintes categorias: 1- critérios de formação de grupos: cor, formato, espessura, tamanho, formação aleatória (mistura de peças de formatos, cores, tamanhos e espessuras diferentes); 2- formação de grupos a partir da utilização de palavras sem sentido (formação do conceito). Esse agrupamento em categorias permitiu organizar os dados da primeira etapa e identificar relações, "sequências, e uniformidade entre os eventos observados" (Dana, \& Matos, 2006, p. 121). Buscou-se relacionar as etapas percorridas pelos participantes para a elucidação dos novos conceitos, os quais permitiram evidenciar a relação entre linguagem não verbal e manipulação de objetos com a formação do conceito.

\section{Discussão e resultados}

O tempo médio na aplicação do instrumento foi de onze minutos e sete segundos. Do total de participantes, $65 \%$ iniciaram a manipulação do instrumento separando as peças conforme um critério verbalizado por eles. Os critérios escolhidos foram: formato (35\%), aleatório (35\%), cor (25\%) e conceito parcial (5\%) (escolha de algumas peças cev, 
porém com formação de um conceito diferente do proposto por Vigotski - tamanho e espessura das peças) respectivamente.

Os participantes que iniciaram a formação de agrupamentos aleatoriamente seguiram um critério para a formação de grupos de peças que tinham uma característica em comum, que podia ser a espessura ou o tamanho. Em $80 \%$ dos casos, geralmente os que iniciaram a formação pelo critério da cor seguiram o reagrupamento pelo critério do formato. O único participante que iniciou o agrupamento fazendo escolha das peças pela palavra cev não formou o conceito de acordo com o critério tamanho e espessura e seus reagrupamentos se deram aleatoriamente. Os demais participantes efetuaram os reagrupamentos posteriores de modo aleatório, até conseguirem um número razoável de peças desviradas, o que permitiu juntar peças do mesmo conceito por meio de eliminação. Ao final da atividade, todos os participantes conseguiram formar os quatro grupos de peças de acordo com a palavra, porém alguns participantes não chegaram a formar o conceito estabelecido pelo experimento. Para $85 \%$ dos participantes, o critério final atribuído às palavras sem sentido referia-se ao tamanho e espessura das peças. Para $5 \%$ dos participantes, o critério final atribuído às palavras sem sentido referia-se apenas ao tamanho, espessura ou alguma forma de encaixe entre as peças. Os outros $5 \%$ dos participantes atribuíram o conceito referente à espessura para as peças cev (peças pequenas e finas) e bik (peças grandes e finas) e tamanho para as peças mur (peças pequenas e grossas) e lag (peças grandes e grossas.

Sete participantes (36\%) primeiramente identificaram mais as diferenças do que as semelhanças entre as peças, apresentando falas como: "Eu acho que essas outras não entram nos grupos...hum...sei lá, não combinam" (sic), "O que elas têm em comum?" (sic).

No caso específico de um participante, pôde-se verificar que após a separação de todas as peças pertencentes aos conceitos cev e bik houve a atribuição do conceito proposto por Vigotski (referentes ao tamanho e espessura das peças), no entanto após a separação dos conceitos lag e mur, seu critério final foi alterado. O único participante que iniciou o agrupamento escolhendo peças do conceito cev (cinco peças de um total de seis) formou um conceito de acordo com o critério de que eram peças de formatos e cores diferentes. Mesmo tendo iniciado a formação de agrupamentos com um critério definido, este não foi utilizado, sendo os reagrupamentos seguintes formados aleatoriamente. Em alguns momentos, mesmo os participantes escolhendo corretamente peças do mesmo conceito, alguns afirmavam não ter certeza quando lhes foi perguntado se a separação das peças seguia algum critério. Outras falas como "Não tem uma lógica, não sei" (sic.), "Eu acho que essas outras não entram nos grupos...hum...sei lá, não combinam" (sic.) foram enunciadas quando o participante separava as peças a partir do mesmo conceito, mas não sabia ao certo qual era o critério do conceito em questão. Outro participante, depois de escolher todas as peças do conceito cev e de estas serem desviradas, disse: "Fui eu que montei?" (sic), o que demonstra a incerteza quanto ao conceito após várias tentativas e reagrupamentos formados sem sucesso.

Um dos participantes, após ter finalizado sua atividade e visto que tinha formado todos os conceitos das palavras, relatou: "Não acredito que demorei tanto tempo", visto que, ao término da atividade, os conceitos das palavras sem sentido pareciam óbvios quando comparados com o início da atividade.

Para $65 \%$ dos participantes a resolução da atividade proposta foi iniciada com um conceito potencial, e ainda aproximadamente $35 \%$ dos participantes desta pesquisa demonstraram ter seguido as três etapas propostas por Vigotski: a fase do sincretismo ou amontoados sincréticos, a fase da formação de complexos ou pensamentos por complexos e a fase de conceitos potenciais.

Em todos os casos foi possível observar que a ação dos participantes era acompanhada pela linguagem verbalizada, o que permitiu acessar o processo de resolução do problema proposto. É digno de nota que, nos casos em que a separação das peças foi aleatória, não estava presente a verbalização, o que conduz à hipótese de que a linguagem não estava orientando o processo como nos demais casos. Novamente fica evidenciada a teoria de Vigotski que estabelece a linguagem como orientadora do pensamento conceitual.

$\mathrm{Na}$ fase da formação de complexos ou pensamentos por complexos os participantes começavam a escolher peças de acordo com alguma característica similar ou complementar (contraste, aproximação entre peças, tamanho, espessura). Ao manipular as peças, o participante tentava organizar o pensamento de modo a resolver a atividade. Para Vigotski, esse tipo de pensamento consiste na combinação de objetos ou impressões que compartilham algum traço similar - fase em que pode ocorrer o complexo concatenado ou a transmissão de um significado para um elemento novo. Os participantes vão formando assim uma cadeia em que um elemento se liga a outro a partir de suas características.

Quanto à fase de conceitos potenciais, os agrupamentos formados pelos participantes referiam-se a alguma característica aleatória das peças, como, por exemplo, o tamanho ou a espessura. Em seguida eram formados novos conceitos nos quais o participante conseguia relacionar as peças do instrumento aplicado e abstrair e generalizar o novo conceito. A formação do novo conceito indicava, assim, a superação das fases anteriores. Conclui-se que a história de aprendizagens e vivências permite ao sujeito construir e reconstruir formas de operar com o conteúdo externo e deste se apropriar, originando outro processo para a resolução dos problemas.

Os participantes que demonstravam já iniciar a atividade proposta com um conceito potencial, por meio da escolha de peças da mesma cor ou formato, perceberam, posteriormente à primeira tentativa, que esses critérios não correspondiam ao conceito da palavra. Isto leva a concluir que houve uma inversão na ordem das fases proposta por Vigotski. Uma hipótese para esta inversão pode ser que a amostra foi composta por participantes adultos nos quais, 
supõe-se, a linguagem já foi internalizada e conduz, em alguma medida, o processo de resolução de problemas. Dessa forma, a atividade teve início com a fase de conceitos potenciais e depois predominaram agrupamentos seguindo o pensamento por complexos. Nestes, as peças com alguma característica similar ou complementar foram sendo escolhidas até se voltar à elaboração de conceitos potenciais e, enfim, à formação dos novos conceitos relacionados às palavras sem sentido.

Observou-se na aplicação do instrumento e análise das gravações que não há unanimidade com relação às etapas percorridas durante a formação do conceito. De modo geral, parte dos participantes observou a sequência das etapas da formação de conceito proposta por Vigotski. Independentemente da sequência de etapas seguidas, quase todos os participantes atingiram a formação de um conceito, relacionando as palavras sem sentido (cev, mur, lag, e bik) com seu tamanho e espessura. Apenas um participante fez referência somente à espessura das peças; outros dois fizeram a relação entre tamanho e espessura, mas acrescentaram características aos conceitos das palavras sem sentido. Apenas um participante ainda relacionou qualidades como cores e formas e outro com alguma forma de encaixe entre as peças. Todos alcançaram o objetivo proposto, atingindo a formação do conceito, muito embora não tenham feito exatamente as associações e combinações entre qualidades das peças conforme o experimento de Vigotski.

\section{Considerações finais}

Esta pesquisa buscou descrever como um novo conceito é internalizado, isto é, verificar se os participantes conseguiram formar um novo conceito e confirmar as fases da formação de conceitos descritas por Vigotski: o sincretismo ou amontoados sincréticos; a formação de complexos e a fase dos conceitos potenciais, considerando o desenvolvimento e organização do pensamento conceitual.

Verificou-se que o processo da formação de conceitos é um tema ainda pouco explorado, o que deixa uma lacuna no conhecimento científico; por isso é necessário desenvolver novas pesquisas. Demonstrou-se o pensamento de Vigotski de que a função de generalização é a função principal da linguagem e que sem ela seria impossível adquirir as experiências anteriores, pois a linguagem não é apenas meio de generalização, mas a base do pensamento. Sobre as etapas percorridas na formação de conceitos não houve nesta pesquisa unanimidade nas respostas dos sujeitos.

Um ponto que contribui para o desenvolvimento das funções psicológicas é a aprendizagem. A aprendizagem ocorre durante a interação do sujeito com o mundo e os grupos sociais. A relação que o sujeito mantém com o seu mundo e suas vivências estimula processos internos e interfere no seu desenvolvimento, que não caminha para um ponto final. O desenvolvimento e a aprendizagem são processos em constante transformação, o que permite ao sujeito dar saltos qualitativos no decorrer de sua vida. Em suas pes- quisas, Vigotski estudou crianças, adolescentes e adultos, dando ênfase aos dois primeiros em suas experiências. As diferenças existentes entre o mundo infantil e o adulto referem-se às mudanças qualitativas que ocorrem ao longo do desenvolvimento do sujeito. Em vista disto, um aspecto a ser explorado em futuras pesquisas seriam as possíveis diferenças entre as trajetórias de formação de conceitos entre pessoas com diferentes níveis de escolarização. $\mathrm{Na}$ presente pesquisa todos os participantes eram estudantes universitários, mas ainda assim os processos de formação de conceitos não foram homogêneos. Uma pesquisa mais aprofundada poderia relacionar mais precisamente escolarização e formação de conceitos.

Segundo Vigotski (1984), as relações e conexões entre as diversas funções psicológicas - como a atenção, a percepção, as operações sensório-motoras e a memória formam sistemas que passam por transformações no decorrer do desenvolvimento da criança e ao longo da vida adulta. Como exemplo tem-se a mudança na relação entre memória e pensamento, que ocorre durante o desenvolvimento: para a criança, "pensar" equivale a "lembrar", enquanto na adolescência o "lembrar" equivale ao "pensar." Na adolescência a memória tem uma capacidade lógica. O fato de lembrar leva a estabelecer e a encontrar relações lógicas, o que significa que trazer algo à memória baseia-se na descoberta de um aspecto que precisa ser encontrado.

Observa-se a mesma relação com a percepção. Conforme o envolvimento do sujeito com outros contextos, como a família e a escola, sua percepção tende a se tornar cada vez mais complexa, captando percepções categorizadas em vez de aspectos irrelevantes para a organização de uma classe de objetos. Nesta pesquisa, optamos por escolher uma única peça para ser utilizada como amostra inicial. Esse procedimento foi adotado com o objetivo de obter um padrão para todos os participantes. Em estudos posteriores poder-se-á encontrar uma alternância entre as peças utilizadas como amostra inicial, o que permitirá verificar se aparecem diferenças no percurso da formação de conceitos. Para futuras pesquisas propomos que o método de Vigotski seja aplicado em uma amostra maior de participantes adultos, e que essa amostra inclua a população infantil, com o intuito de verificar se ocorrem divergências nas etapas percorridas e se o método pode servir como um meio de avaliar o momento de desenvolvimento da criança com vistas a uma intervenção que favoreça o desenvolvimento do pensamento conceitual.

\section{Referências}

Cazeiro, A., P., M., \& Lomônaco, J., F., B. (2011). Formação de conceitos por crianças com paralisia cerebral: um estudo exploratório sobre a influência de atividades lúdicas. Psicologia. Reflexão e Crítica, 24 (1). Porto Alegre, 40-50.

Danna, M., F., \& Matos, M., A. (2006). Aprendendo a observar. São Paulo. Edicon. 
Gerhardt, A., F., L., M. (2010). Integração conceptual, formação de conceitos e aprendizado. Revista Brasileira de Educação, 15 (44). Rio de Janeiro, 247-263.

Goes, M., C., R., \& Cruz, M., N. (2006). Sentido, significado e conceito: notas sobre as contribuições de Lev Vygotsky. Proposições, 17, 31-45.

Luria, A., R. (1987). Pensamento e linguagem: as últimas conferências de Luria. Porto Alegre: Artes Médicas.

Montoya, A., O., D. (2006). Pensamento e linguagem: percurso Piagetiano de investigação. Psicologia em Estudo, 11 (1), 119-127.

Moreira, M., A., Caballero, M., C., \& Rodriguez, M., L. (Orgs.) (1997). Actas del Encuentro Internacional sobre el Aprendizaje Significativo (pp. 19-44). Burgos, España.

Nébias, C. (1998). Formação dos conceitos científicos e práticas pedagógicas. Interface - Comunicação, Saúde, Educação, 3(4), 133-140.
Piaget, J. (1996). A construção do real na criança. São Paulo: Ática.

Pozo, J., I. (1998). Teorias cognitivas da aprendizagem. Porto Alegre: Artes Médicas.

Skinner, B. F. (2003). Ciência e comportamento humano. São Paulo: Martins Fontes.

Vygotsky, L., S. (1984). A Formação Social da mente. São Paulo: Martins Fontes.

Vygotsky, L., S. (1994). Obras Escogidas. España: Ed. Visor.

Vygotsky, L., S. (1998). Pensamento e linguagem. São Paulo: Martins Fontes.

Vygotsky, L., S. (2000). A construção do pensamento e da linguagem. São Paulo: Martins Fontes.

\section{Sobre as autoras}

Maria Sara de Lima Dias (maria.dias@utp.br, msaradldias@gmail.com)

Doutora em Psicologia pela UFSC - Professora do curso de Mestrado em Psicologia Social Comunitária pela UTP (Universidade Tuiuti do Paraná) e Professora do Curso de Psicologia da Universidade Positivo.

Roberta Kafrouni (rkbeta@hotmail.com)

Doutora em Psicologia pela PUC-SP - Professora do curso de Mestrado em Psicologia Social Comunitária pela UTP (Universidade Tuiuti do Paraná).

Camilla Silva Baltazar (miilasb@yahoo.com.br)

Graduanda do Curso de Psicologia da Universidade Positivo.

Juliana Stocki (Juliana_stocki@hotmail.com)

Graduanda do Curso de Psicologia da Universidade Positivo.

Trabalho apresentado no III Encontro de Pesquisa e Iniciação Científica (EPIC) - EPIC 2012 